\title{
O PROCESSO INCLUSIVO NOS MUNICÍPIOS DE ARARAS E ALFENAS NO ENTENDIMENTO DE LICENCIANDOS BOLSISTAS DO PIBID
}

\section{EL PROCESO INCLUSIVO EN LOS MUNICIPIOS DE ARARAS Y ALFENAS EN LA COMPRENSIÓN DE ALUMNOS DE GRADO BECARIOS DEL “PIBID”}

\section{CONCEPTIONS OF STUDENTS WITH PIBID SCHOLRASHIP ABOUT THE INCLUSIVE PROCESS IN THE TOWNS OF ARARAS AND ALFENAS}

\author{
Fernanda Vilhena Mafra BAZON ${ }^{1}$ \\ Daniele LOZANO ${ }^{2}$ \\ Claudia GOMES ${ }^{3}$
}

RESUMO: Este trabalho foca a investigação das concepções e experiências de licenciandos, bolsistas do Programa Institucional de Bolsas de Iniciação à Docência (Pibid) no que tange à educação especial e inclusão escolar em dois municípios: Araras (SP) e Alfenas (MG). Participaram desta pesquisa 37 licenciandos de universidades federais, que responderam a questionários contendo questões abertas e fechadas. Alguns dos resultados apontaram que 57,1\% dos licenciandos de Araras e 60,9\% dos de Alfenas, indicam possuir o conhecimento sobre legislações que amparam a educação inclusiva. Em Araras: 76,9\%, e em Alfenas: 60,9\% dos alunos participaram de eventos e cursos voltados à educação especial ou inclusiva, mas $76,9 \%$ e $82,6 \%$ dos alunos respectivamente consideravam-se despreparados para atuar em sala de aula com alunos com NEE. Este fato pode estar amparando o posicionamento de 38,5\% dos discentes de Araras e $39,1 \%$ de Alfenas ao não considerarem ser de sua responsabilidade executar práticas educacionais para esses alunos em escolas regulares. Ressaltamos que este estudo apontou para a necessidade de discussão crítica acerca da temática inclusiva na formação inicial e que o Pibid possa ser considerado lócus privilegiado para a mesma, ao poder favorecer a interface entre teoria e prática.

PALAVRAS-CHAVE: Formação docente. Inclusão educacional. Pibid.

RESUMEN: Este trabajo se centra en la investigación sobre las concepciones y experiencias de alumnos de grado, becarios del Programa Institucional de Becas de Iniciación a la Docencia (PIBID) en lo que se refiere a la educación especial e inclusión escolar en dos ciudades: Araras (SP) y Alfenas (MG). Participaron de esta investigación 37 alumnos de grado de universidades federales, que respondieron a cuestionarios con cuestiones abiertas y cerradas. Algunos de los resultados indicaron que el 57,1\% de los alumnos de grado de Araras y el 60,9\% de los de Alfenas indican poseer conocimiento sobre legislaciones que sostienen la educación inclusiva. En Araras: el 76,9\%, y en Alfenas: el 60,9\% de los alumnos participaron de eventos y cursos orientados a la

\footnotetext{
${ }^{1}$ Doutora em Educação. UFSCar - Universidade Federal de São Carlos. Professora do Departamento de Ciências da Natureza, Matemática e Educação. Email: febazonccaufscar@gmail.com

2 Mestre em Matemática Aplicada. UFSCar - Universidade Federal de São Carlos. Professora do Departamento de Ciências da Natureza, Matemática e Educação. Email: lz.daniele@ gmail.com

3 Doutor em Psicologia. UNIFAL - Universidade de Alfenas. Professora do Instituto de Ciências Humanas. Email: cg.unifal@gmail.com
} 
educación especial o inclusiva, pero el $76,9 \%$ y el $82,6 \%$ de los alumnos respectivamente se consideraban poco preparados para actuar en sala de clase con alumnos con NEE. Este hecho puede tener amparo en el posicionamiento del 38,5\% de los discentes de Araras y del 39,1\% de Alfenas por no considerar ser de su responsabilidad ejecutar prácticas educacionales para esos alumnos en escuelas regulares. Destacamos que este estudio muestra la necesidad de la discusión crítica sobre la temática inclusiva en la formación inicial y que el PIBID pueda ser considerado un espacio privilegiado para eso, por poder favorecer la articulación entre teoría y práctica.

PALABRAS CLAVE: Formación docente. Inclusión educacional. PIBID.

ABSTRACT: This study looks for the analysis of the conceptions of graduation students, with scholarship of the Programa Institucional de Bolsas de Iniciação à Docência (Pibid), about the special education and of the inclusive education in the towns of Araras (SP) and Alfenas MG). Participated of this research 37 students of federal universities situated in the referred towns. It was utilized a questionnaire with open and closed questions for the study. The results aimed that $57.1 \%$ of the students of Araras and $60.9 \%$ of the students of Alfenas, have the knowledge about legislations that support the inclusive education. In Araras: 76,9\%, and in Alfenas: $60.9 \%$ of the students participated of events and courses abaout special education or school inclusion, but $76.9 \%$ (Araras) and $82.6 \%$ (Alfenas) considered themselves unprepared to act in classroom with students with special needs. This fact may be supporting some present conceptions in the two towns, for example, $38.5 \%$ of the students of Araras and $39.1 \%$ of the students of Alfenas considered that there are not theirs responsibility to perform educational practices for those students in regular schools, attributing this fact to problems in their courses of graduation. We emphasize that this study pointed to the need for critical discussion of scholar inclusion in initial training and the Pibid can be considered a privileged place for it.

KEYWORDS: Special education. Professor formation. Educational inclusion.

\section{Introdução}

Este trabalho focaliza a investigação das concepções e experiências de licenciandos, bolsistas do Programa Institucional de Bolsas de Iniciação à Docência (Pibid) no que tange à educação especial e inclusão escolar, bem como busca analisar a atuação destes discentes no âmbito do Pibid em dois municípios da região sudeste: Araras (SP) e Alfenas (MG). Estes dois municípios foram selecionadas em decorrência da semelhança do histórico dos cursos de licenciatura e participação no Programa de Reestruturação e Expansão das Universidades Federais (REUNI) pelas duas instituições envolvidas, bem como pela parceria firmada entre pesquisadores da Universidade Federal de São Carlos - Campus Araras e Universidade Federal de Alfenas no 
desenvolvimento de estudos que visem à compreensão das práticas inclusivas atuais e suas concepções subjacentes, contando para tanto com o apoio da FAPESP e FAPEMIG

Voltando-nos para a proposta inclusiva e seu desenvolvimento político no Brasil, desde a Constituição Federal de 1988 notamos a elaboração e implantação de diversos dispositivos legais que buscam subsidiar as ações educacionais para atender a diversidade humana, havendo predomínio em se determinar a escola regular como espaço de preferência para o atendimento de alunos com Necessidades Educacionais Especiais (NEE). Em 2008 a Política Nacional de Educação Especial na perspectiva da Educação Inclusiva, definiu a modalidade da educação especial como campo do conhecimento que pode auxiliar de forma transversal o ensino regular, em seus diferentes níveis, e não mais substituí-lo como historicamente foi realizado nas esferas educacionais do país. A compreensão assumida pela resolução deixa claro que a inclusão escolar é ação política, cultural, social e pedagógica, desencadeada em defesa do direito de todos os alunos de estarem juntos, aprendendo e participando do ambiente escolar sem nenhum tipo de discriminação.

Cabe ressaltar, que com a promulgação do Decreto n. 7.611, que dispõe sobre a educação especial e o atendimento educacional especializado (AEE), modificaram-se premissas da Política de 2008, uma vez que volta a ser permitida a oferta da modalidade de ensino especial, preferencialmente na rede regular, porém, não exclusivamente. A recente Lei 13.146 de 2015 mantém esta disposição, sendo portanto o ensino regular locus preferencial de atendimento. Diversas discussões vêm sendo realizadas na área acerca de um possível retrocesso do decreto 7.611 (BRASIL, 2011), entretanto estas não fazem parte do objetivo deste trabalho. Podemos refletir apenas que com base nesses aspectos não é possível levar a cabo qualquer proposta de inclusão escolar sem considerar as especificidades dos professores - sua história, sua formação, suas prédisposições para se engajar no processo - sendo então essencial discutirmos a formação inicial e como o Pibid, programa que teve grande destaque nos últimos anos e que atualmente passa por instabilidades, pode se constituir como forma de auxílio para o estabelecimento de licenciaturas que levem em consideração a escola inclusiva e democrática, bem como as práticas pedagógicas voltadas para a diversidade de alunos encontrados nas salas de aula.

O Pibid faz parte de diversas ações governamentais que focam a valorização do magistério e a melhoria da qualidade e expansão ao acesso ao ensino superior. 
Entretanto, se por um lado, a consideração e o investimento das esferas públicas nesse processo de formação e qualificação docente são divulgados por diferentes programas e propostas, como o Pibid e o REUNI, por outro, avaliações específicas nos parecem necessárias para entender os impactos das ações desenvolvidas.

No que se refere ao Pibid, este programa foi criado visando à valorização do magistério e o apoio aos alunos de cursos de licenciatura das instituições de educação superior públicas e comunitárias sem fins lucrativos. Dentre seus objetivos estão a elevação da qualidade das ações acadêmicas voltadas à formação inicial de professores nos cursos de licenciatura e a inserção dos alunos destes cursos nos cotidianos das escolas públicas, promovendo assim a relação mais próxima entre educação superior e educação básica. Além disso, o programa busca proporcionar aos licenciandos experiências metodológicas, tecnológicas e práticas docentes interdisciplinares e inovadoras com vistas a superar problemas identificados no processo de ensinoaprendizagem.

André (2012), ao analisar as políticas e programas de apoio aos professores iniciantes no país, aponta, assim como Ambrosetti, Ribeiro e Teixeira (2011), que apesar de não haver uma avaliação abrangente dos efeitos do Pibid na formação docente, tem-se verificado "resultados muito positivos, seja na motivação dos estudantes envolvidos, para ingressar na profissão, seja na disposição dos professores das escolas, que se sentem desafiados a rever suas práticas em colaboração com os novos atores do ambiente escolar" (p. 126).

Em breve levantamento realizado no Scielo, foram encontrados 19 artigos que tratam do Pibid, sendo que em sua maioria apresentam interface positiva entre o programa e a formação de professores, tanto inicial quanto continuada. Santos e Arroio (2015) afirmam que na experiência do Pibid de Química da USP foi constituída uma comunidade de prática que auxiliou na aprendizagem e na formação docente dos licenciandos. Darroz e Wanmacher (2015) também analisam os efeitos positivos do Pibid na formação de professores de física no Rio Grande do Sul, apontando que

Com efeito, evidenciou-se, nos relatos analisados, que, no decorrer das atividades, os bolsistas adquirem conhecimento prático da docência por meio da ação e com base na reflexão na ação, ampliando seu interesse pela área. $\mathrm{Na}$ elaboração, na implementação e na avaliação das atividades, trabalham a capacidade de refletir sobre a docência e de partilhar experiências com colegas e demais personagens do processo de ensinar e aprender, desenvolvendo, dessa 
forma, a reflexão coletiva. Ainda, identificando-se como aprendizes da docência, procedem à construção de sua identidade docente (DARROZ \& WANMACHER, 2015, p. 746).

Pensar o professor, atualmente, nos remete a repensar formas mais democráticas e emancipatórias, propícias para o desenvolvimento humano dos educadores como agentes de posicionamento e transformação. No entanto, esta ação envolve situar a organização escolar em um contexto social mais amplo, dentro de concepção mais realista, que considere os valores, os significados, as interpretações pessoais de cada profissional (LIBÂNEO; TOSCHI; ALMEIDA, 2012).

Assim, no que se refere às ações docentes em relação à temática da educação inclusiva, diversos estudos parecem alertar para a importância de maior atenção na implementação das políticas, enfatizando que a proposta só será efetivada com sucesso quando compreendida como consequência de discussão da necessidade de mudança do paradigma educacional vigente. Esta mudança de paradigma deve dar ênfase ao maior compromisso com a diversidade humana e com as transformações das representações das diferenças (BASTOS, 2003; PESSINI, 2002, BUENO, 2011).

Diferentes autores, que abordaram o contexto educacional e suas dificuldades frente à proposta educacional inclusiva, apontam que as barreiras para o processo parecem polarizar a discussão da contextualização dos valores mais implícitos da proposta, tais como o clima escolar e as resistências, que por ventura possam ser vivenciadas pelos protagonistas envolvidos, assim como uma formação acadêmica satisfatória, que seja relacionada à reflexão e à abordagem das diferenças (EMILIO, 2004; VIANA, 2005; FRANCA, 2005).

Focar em ações de formação e atuação profissional que insiram os educadores em novas esferas de compreensão e vivência da proposta inclusiva (nas quais possam questionar, discordar, elaborar e criar ações de enfrentamento cotidiano), que embasem a autenticidade profissional de cada docente é uma das considerações necessárias e centrais para a configuração de novos sentidos acerca da inclusão.

Tendo em vista estas considerações, este estudo teve como objetivo discutir a formação inicial de professores a partir da experiência de alunos que participam do Pibid por pelo menos um ano, tendo em vista as interfaces entre a formação docente e a inclusão de alunos com necessidades educacionais especiais no ensino regular. 


\section{Metodologia}

Com base no objetivo deste estudo optamos pelo delineamento inicial de uma pesquisa exploratória e com abordagem quantitativa e qualitativa, pautada em questionários respondidos por 37 bolsistas do Pibid nas cidades de Alfenas e Araras. O estudo foi dividido em duas etapas, sendo a primeira composta pela análise dos dados quantitativos por meio de provas de estatísticas descritivas e inferencial com a utilização do software Statistical Package for the Social Science for Windows (SPSS); e a segunda etapa baseou-se na análise das questões abertas dos questionários que proporcionaram entendimento mais aprofundado das concepções e práticas dos bolsistas e sua interrelação com o processo inclusivo nos municípios selecionados.

No que se refere ao instrumento de pesquisa, os questionários foram compostos por questões objetivas e abertas que visavam caracterizar: formação; atuação profissional; conhecimento da temática inclusiva; preparação e formação inicial para a inclusão escolar. Conforme apontado anteriormente, o instrumento foi avaliado por meio de projeto piloto para analisar sua abrangência e consonância com os objetivos propostos. Além disso, todos os informantes assinaram o termo de consentimento livre e esclarecido.

Para a análise da significância dos dados coletados, foi utilizado o Teste do QuiQuadrado de um critério ${ }^{4}$, com nível de significância 0,05.

Os informantes desta pesquisa foram 37 licenciandos, bolsistas do Pibid das universidades públicas federais localizadas nos municípios de Araras e Alfenas. A seguir estão dispostas as características dos informantes por cidade pesquisada:

- UNIFAL: 23 pibidianos, sendo 20 do sexo feminino e 3 do sexo masculino, com idade entre 20 e 41 anos, do curso de Pedagogia; sendo 69,3\% (N=16) dos participantes vinculados ao programa a menos de um ano. Pibidianos atuantes no primeiro ciclo do ensino fundamental e com atuações voltadas também para o ensino de ciências nesta etapa educacional.

- UFSCar-Campus Araras: 14 pibidianos, sendo 7 do sexo feminino e 7 do sexo masculino, com idade entre 20 e 46 anos, dos cursos de licenciatura em Química, Física e Ciências Biológicas, e em sua maioria vinculados ao programa de um a dois anos $(85,7 \% ; \mathrm{N}=12)$. Pibidianos atuantes no segundo ciclo do ensino fundamental, vinculados à disciplina de ciências.

${ }^{4}$ Este teste tem como principal objetivo testar se a distribuição observada difere de maneira significativa de uma distribuição esperada (LEVIN, 2012). 


\section{Resultados e discussão}

A compreensão assumida pelas atuais resoluções que amparam a inclusão escolar, como ação política, cultural, social e pedagógica, visualizada pela defesa do direito à escolarização de todos os alunos indistintamente, tem como desafio central de análise: a discussão da formação docente para a inclusão.

Inicialmente cabe ressaltar que sabemos das diferenças inerentes nos cursos de formação de professores focados nesta pesquisa, já que a Pedagogia forma professores para a Educação Infantil e primeiro ciclo do Ensino Fundamental e as licenciaturas em Química, Física e Ciências Biológicas forma para o segundo ciclo do Ensino Fundamental e Ensino Médio. Entretanto, alguns fatores aproximam a atuação destes licenciandos no Pibid das universidades em questão, já que todos eles atuam no ensino fundamental e possuem interface no ensino de ciências, no primeiro ciclo para a Pedagogia e no segundo ciclo para as licenciaturas em Química, Física e Ciências Biológicas.

Outro fator que favorece a reflexão conjunta é que os cursos de licenciatura do Campus Araras da UFSCar possuem viés interdisciplinar e integrador, com principal foco na formação docente e busca constante de trabalho cooperativo (inclusive no Pibid) entre os professores da área específica e pedagógica, de forma a buscar o distanciamento do modelo "3+1", que conforme Gatti (2009) predominou na formação de professores por um longo período. Nestes cursos a formação docente é o objetivo norteador das ações, sendo que o Pibid vem a contribuir para a maior integração entre docentes, discentes e professores supervisores das escolas envolvidas. Sendo assim, apesar das diferenças entre os cursos, acreditamos ser válida a reflexão conjunta, de forma a buscar constituir uma visão de licenciatura que tenha como objetivo primeiro a formação docente, valorizando assim uma carreira que encontra diversos desafios no atual cenário político e econômico.

Por fim, precisamos estar atentos ao fato de que todos os cursos de formação docente - seja Pedagogia ou licenciatura em Química, Física, Ciências Biológicas, entre outras - devem oportunizar cabedal teórico e discussões críticas acerca da inclusão escolar. Consideramos que a presença desta temática na formação inicial de professores é fator fundamental para o desenvolvimento de uma educação democrática, que atenda as necessidades educacionais dos alunos com e sem deficiência. 
Levando em consideração estas questões, neste estudo, dentre os elementos de análise debruçamo-nos sobre a preparação inicial docente, contemplando os seguintes questionamentos: o conhecimento das políticas e legislações que amparam a questão inclusiva; participação em cursos e eventos que abordem a temática; concepção pessoal e profissional da responsabilidade e competência em dedicar atenções educacionais a alunos com NEE (Tabela 1).

Tabela 1: Preparação inicial para atuar com alunos com NEE

\begin{tabular}{l|c|c|c|c|c}
\hline & \multicolumn{3}{c}{ Araras } & \multicolumn{3}{c}{ Alfenas } \\
\hline Conhecimento sobre políticas vinculadas à educação inclusiva & Sim & Não & Sim & Não \\
\hline Participação em cursos vinculados à educação inclusiva & 11 & 6 & 14 & 9 \\
Preparação para trabalhar com alunos com NEE & 4 & 14 & 9 \\
Responsabilidade por atuar com alunos com NEE & 9 & 5 & 14 & 9 \\
\hline
\end{tabular}

Fonte: autoras

Os resultados em relação ao conhecimento das políticas educacionais inclusivas indicam que na cidade de Araras, 57,1\% (N=8) dos licenciandos apontam conhecer as políticas em questão. Assim como-, na cidade de Alfenas, 60,9\% ( $\mathrm{N}=14)$ apontam o conhecimento das legislações que cercam o cenário legal das propostas educacionais inclusivas. Tanto no município de Araras $\left(\chi^{2}=0,28 ; \mathrm{ngl}=1 ; p=0,59\right)$, como em Alfenas $\left(\chi^{2}=1,08 ; n g l=1 ; p=0,29\right)$, não há diferença significativa entre os licenciandos que apontam ter conhecimento das leis e políticas educacionais inclusivas e os que desconhecem os embasamentos legais. Estes resultados nos apontam que mesmo com uma porcentagem de alunos que indicam o conhecimento legal e jurídico da proposta, este número não se traduz em uma parcela significativamente conhecedora do tema, na perspectiva política.

Tanto em Alfenas quanto em Araras os alunos atribuíram o conhecimento dos documentos e normativas políticas às disciplinas obrigatórias ou optativas existentes em seus cursos. Notamos então que a formação inicial assume papel preponderante no contato dos alunos com as legislações pertinentes à educação especial e inclusiva, já que a maioria dos que afirmam ter conhecimento sobre as mesmas, o tem em decorrência dos cursos de graduação. Porém cabe aqui um esclarecimento que traz preocupação, já que no currículo das licenciaturas da UNIFAL os discentes contam com disciplinas que abordam especificamente as discussões acerca da educação especial e inclusiva, favorecendo assim a formação inicial que leve em consideração a diversidade de necessidades educacionais e o atendimento destas necessidades. Na UFSCar a situação 
não é a mesma, já que em seu currículo as licenciaturas do campus de Araras não contam com qualquer disciplina que se volte às práticas educacionais inclusivas, sendo que este tema é tratado apenas no ensino de LIBRAS.

Esta consideração é importante, pois se buscamos a construção de uma escola que atenda aos alunos com NEE precisamos investir de forma incisiva na formação inicial dos futuros docentes. Ao avaliarmos a história da educação de pessoas com deficiência, parcela significativa dos alunos com NEE, vemos que mesmo que teóricos como Vigotski na primeira metade do século XX já apontassem para os problemas da segregação, ainda vivemos em embate contra o encaminhamento à escolarização segregadora, luta permeada por posicionamentos teóricos e políticos diversos. Desta forma, o investimento no aprofundamento das discussões sobre o processo inclusivo nos espaços de formação inicial é essencial para a modificação dos sentidos da inclusão e exclusão vivenciados atualmente.

Voltando ao conhecimento da legislação, apesar de considerarmos a grande importância da discussão dos aparatos legais que dão suporte e norteiam a educação inclusiva, esta discussão não garante a efetividade do processo, muito pelo contrário, o que visualizamos de modo geral, em relação à inclusão de alunos com NEE, é um abismo entre as intenções políticas e as realidades vividas nas escolas. Porém, entendemos que a compreensão crítica das políticas e ações que mantém a discussão sobre a inclusão escolar é um aprendizado essencial para a formação docente.

Considerando que não é apenas a necessidade da formação política e legislativa que envolve a questão educacional inclusiva, mas também aspectos vinculados à formação prática profissional, pôde-se constatar neste estudo, que no que se refere à participação em cursos e eventos sobre o processo educacional inclusivo de alunos com NEE, em ambos os municípios os participantes indicam terem participado de eventos formativos centrados na temática da inclusão (Araras: 78,6\%; N=11; Alfenas: 60,9\%; $\mathrm{N}=14)$.

No entanto, na cidade de Araras, dos quatorze licenciandos, onze afirmam terem participado de cursos e palestras sobre o tema, mas preocupantemente, apenas quatro apontam ter recebido preparação para trabalhar com alunos com NEE. Já na cidade de Alfenas, evidencia-se que dos vinte e três licenciandos, apenas quatorze afirmam terem participado deste tipo de evento, e somente três apontam ter recebido preparação para o trabalho específico com alunos com NEE. O teste Qui-Quadrado nos mostra que há em Araras uma diferença significativa no que se refere à participação em cursos voltados à 
educação inclusiva $\left(\chi^{2}=4,571 ; \mathrm{ngl}=1 ; p=0,033\right)$, porém em Alfenas esta diferença não se mostra significativa $\left(\chi^{2}=1,087 ; \mathrm{ngl}=1 ; p=0,297\right)$.

Com base nos resultados apresentados, devemos questionar a forma como os cursos e eventos preparatórios oferecidos estão sendo significados pelos discentes, bem como sua relação com as práticas educacionais desenvolvidas no Pibid. De modo geral, os licenciandos apontaram que tais eventos formativos não parecem acrescentar conteúdos e conhecimentos às suas práticas profissionais em relação aos alunos com NEE. Defendemos a necessidade de qualificação dos processos de formação inicial docente, entretanto, acreditamos que a realização de eventos formativos deve acima de tudo estar atrelada à compreensão da inclusão como uma proposta que dê conta das ações excludentes que cercam as escolas. Desta forma, quando os alunos apontam não terem recebido preparação, não podemos deixar de considerar que muitas vezes o entendimento atrelado a esta preparação pode estar embasado por uma tecnicidade das ações educacionais aplicadas aos alunos com NEE, e não efetivamente-; a instauração de práticas pedagógicas democráticas.

Outro ponto a ser levado em consideração diz respeito à forma como o Pibid é estruturado, já que neste programa o licenciando desenvolve atividades curriculares e extracurriculares nas escolas sob supervisão de um professor da escola regular e um professor da universidade. Em estudo complementar a esta pesquisa (BAZON; LOZANO; GOMES, 2013), constatamos que os supervisores que atuam no Pibid tanto em Araras quanto em Alfenas de forma geral não consideram de sua responsabilidade o atendimento a alunos com NEE nas salas de aula regulares, pois entre outros motivos apresentados, não se consideram preparados para desenvolver práticas educacionais com estes alunos. Entretanto, apesar de apontarem para a falta de preparação, muitos dos supervisores contaram com apoio de profissionais da educação especial ou participaram de cursos de formação e pós-graduação lato sensu com temática voltada à inclusão. Este fato nos aponta para um desafio enfrentado no Pibid que é como favorecer a vinculação entre discussões e análises legais e teóricas com a prática desenvolvida pelos bolsistas, tendo em vista que grande parte dos supervisores não possui uma postura inclusiva nas próprias salas de aula. Não há posicionamento por parte dos professores contra a inclusão, mas em seu discurso e no contraponto com as respostas dadas pelos pibidianos verificamos que a inclusão perversa e marginal, tal como proposta por Amaral (2002), Mendes (2002) e Patto (2008), são preponderantes. 
A pouca vinculação apontada pelos discentes entre o cotidiano escolar vivenciado por eles no contexto do Pibid e as análises e discussões favorecidas nos cursos de formação inicial, influencia o entendimento sobre a responsabilidade em dedicar atenção às práticas educacionais desenvolvidas para os alunos com NEE nas salas de aulas regulares. Os resultados apontam que há ainda uma porcentagem representativa $(37,5 \%(\mathrm{~N}=5)$ no município de Araras e 39,1\% (N=9) no município de Alfenas) que não considera ser de sua responsabilidade e competência desenvolver atividades pedagógicas para alunos com NEE no ensino regular. Apesar desta porcentagem não se mostrar significativa ao analisarmos os dados a partir do teste QuiQuadrado em ambos os municípios (Araras: $\chi^{2}=1,143 ; \mathrm{ngl}=1 ; p=0,285$; Alfenas: $\chi^{2}=$ 1,087; ngl=1; $p=0,297)$, não podemos deixar de nos voltar a ela, pois notamos no discurso dos discentes em processo de formação o reflexo do contato com os professores já atuantes na educação básica.

Sobre esta questão, no que se refere à legislação, notamos que no Brasil as determinações referentes ao atendimento de alunos com NEE avançaram muito, assim como também os programas de apoio e incentivo à formação inicial e continuada, como, por exemplo, o REUNI, que proporcionou a criação de grande número de cursos de licenciaturas em todo o país, com vistas a atender a demanda de professores para a educação básica.

Entretanto, entendemos que as políticas e legislações precisam estar vinculadas a práticas responsáveis e concernentes à busca por uma educação de qualidade e democrática. Esta relação entre as determinações legais e práticas educacionais vigentes ainda encontra grandes desafios, incluindo a quebra de barreiras atitudinais que podem ser notadas, por exemplo, ao questionarmos os pibidianos acerca da responsabilidade em desenvolver práticas educacionais com alunos com NEE.

Para Gatti (2009), repensar o desenho para a formação docente, indica a necessidade de espaços que possibilitem aos professores rever suas próprias atitudes e valores, espaços que visualizem uma compreensão integradora das atividades educacionais e a construção de posicionamentos crítico-sociais, articulação esta desafiadora tanto para as políticas governamentais, como para as instituições formadoras.

O fato de $37,8 \%(\mathrm{~N}=14)$ sob o total de bolsistas não considerarem de sua responsabilidade a execução de estratégias pedagógicas inclusivas é preocupante, pois além de estarmos tratando de discentes que ainda estão cursando sua formação inicial, 
os mesmos participam de um programa que visa justamente estreitar as relações desta formação com a escola básica. Notamos que o discurso, muitas vezes encontrado na academia, de que o professor da escola básica é contra a inclusão, pois teve uma formação deficitária, poderá se perpetuar se os cursos de licenciaturas e ações governamentais não forem estruturados de forma a proporcionar uma atuação inclusiva significativa de seus licenciados.

Nas respostas abertas da questão "Você considera ser de sua responsabilidade e competência desenvolver práticas educacionais com alunos com NEE na rede regular de ensino? Por quê?", algumas colocações se destacam, tais como: “Não, porque essas práticas devem ser institucionalizadas para centralizar as melhores metodologias elou conhecimentos (...)" (informante 3-Al); "Não, porque não me sinto preparada" (informante 6-Ar); "Sim. Mesmo não estando preparado, não posso deixar meu aluno incluso marginalmente. É muito difícil o professor com despreparo dar conta (...”) (informante 10-Ar); "Não. Pois acredito que esta é uma tarefa que deve estar voltada para pessoas que se profissionalizaram na área de educação especial, sendo que o trabalho de uma pessoa qualquer pode marginalizar a inclusão" (informante 13-Al).

Notamos nas respostas que mesmo o aluno que se coloca como responsável pelo desenvolvimento de estratégias educacionais com alunos com NEE na sala de aula regular ressalta o problema da falta de preparação para isso. Ao pensarmos que estes alunos ainda estão cursando a licenciatura, afirmar a falta de preparo nos aponta para duas questões: primeiro que as disciplinas voltadas à educação especial e inclusiva precisam contemplar o conhecimento teórico em sua relação com as práticas desenvolvidas em sala de aula; e segundo que muitos dos cursos de licenciatura não comportam em suas grades disciplinas que contemplem estas questões, conforme já tratado neste texto. Tendo isso em vista, o Pibid pode se configurar como lócus privilegiado para a discussão e desenvolvimento de práticas pedagógicas inclusivas que estejam atentas as necessidades dos alunos atendidos e à função social e histórica da escola.

Além disso, na resposta dos informantes 3 e 13 fica latente também a questão de que as melhores metodologias e conhecimentos não seriam de fácil acesso às escolas regulares, devendo ser desenvolvidas por profissionais especializados. Este fato foi discutido por Michels (2006) ao fazer a análise das atribuições dos professores especializados e capacitados, já que esta determinação legal divide o trabalho no interior 
da própria escola, favorecendo comportamentos de pouca responsabilização e segregação ao se tratar de alunos com NEE na escola regular.

Ao se eximirem da responsabilidade por práticas educacionais inclusivas, os licenciandos e licenciados podem favorecer a perpetuação de práticas perversas de inclusão, as quais inserem o aluno no ambiente escolar sem fornecer condições de permanência e apropriação de conhecimento. Se conforme aponta Saviani (2008) a instituição escolar é o local no qual os indivíduos podem se apropriar do conhecimento historicamente acumulado e valorizado socialmente, a simples matrícula de um aluno com NEE na escola regular não pode ser chamada de inclusão, já que não garante a este aluno a participação na produção e apropriação do conhecimento científico.

Na tabela 2, apresentamos os resultados em relação a preparação, atuação e apropriação de conhecimentos de estratégias pedagógicas para atuar com alunos com NEE.

Tabela 2: Atuação em sala de aula e conhecimentos de estratégias pedagógicas para atuar com alunos com NEE.

\begin{tabular}{l|c|c|c|c}
\hline & \multicolumn{3}{c}{ Araras } & \multicolumn{3}{c}{ Alfenas } \\
\hline & Sim & Não & Sim & Não \\
\hline Já atuou em classes com alunos com NEE & 9 & 5 & 6 & 17 \\
$\begin{array}{l}\text { Conhecimento de estratégias pedagógicas para } \\
\text { atuar com alunos com NEE }\end{array}$ & 4 & 10 & 8 & 15 \\
\hline
\end{tabular}

Fonte: autoras

Ao analisarmos a tabela 2 conjuntamente com a tabela 1, verificamos que a atuação em sala de aula com alunos com NEE, aponta que no município de Araras, dos quatorze alunos vinculados ao Pibid, nove (64,3\%) já atuaram em salas de aulas inclusivas. Entretanto, relacionando esta questão quanto à participação em eventos e conhecimento das estratégias pedagógicas inclusivas, constata-se que, dos onze licenciandos que afirmam terem participado de cursos e palestras sobre o tema, apenas quatro deles considera que tais atividades foram favoráveis para a compreensão das estratégias pedagógicas que contemplem os alunos em processo de inclusão escolar.

Já no município de Alfenas, dos vinte e três pibidianos, apenas seis afirmaram terem atuado em salas de aula com alunos com NEE, e quatorze indicaram a participação em cursos e palestras sobre a temática, mas assim como o ocorrido em Araras, somente três dos licenciandos- expressam que a participação nessas atividades foram positivas em relação à preparação efetiva para a atuação em salas de aula inclusivas. 
Em Araras foi evidente que apesar da maioria dos discentes ter atuado em salas de aula com alunos com NEE, poucos receberam preparação para tanto, assim como indicam não possuir conhecimento de estratégias educacionais inclusivas. De forma preocupante, no que concerne à preparação, $71,4 \%(\mathrm{~N}=10)$ da amostra do município de Araras e 82,6\% (N=19) da amostra da cidade de Alfenas, afirmam não possuírem capacitação profissional para atuar com estes alunos. Além disso, apenas 28,6\% ( $\mathrm{N}=4)$ dos licenciandos de Araras e 34,8\% (N=8) dos licenciandos de Alfenas, indicam possuir conhecimento de estratégias pedagógicas inclusivas.

Para buscar um entendimento mais contextualizado desta questão foi realizado o cruzamento das respostas dos pibidianos no que se refere à questão de terem experiência com alunos com NEE e receberem preparação para conduzir esta experiência. Verificamos que no que se refere à cidade de Araras, metade dos pibidianos que tiveram experiência com alunos com NEE em suas atividades não receberam preparação para tanto, o que não ocorre em Alfenas, já que todos os bolsistas obtiveram a preparação para o desenvolvimento de suas ações. Esta questão é importante, pois ao investigarmos a formação profissional para a atuação com alunos com NEE, é essencial que os discentes dos cursos de licenciatura apropriem-se de conhecimentos vinculados à educação especial e inclusiva, bem como às características das NEE e as discussões políticas e acadêmicas desenvolvidas na área.

Aqui podemos levantar a problemática da diferença entre as dinâmicas curriculares da UNIFAL e UFSCar. A diferença na grade curricular no que se refere à presença de conteúdos voltados ao processo educacional de alunos com NEE é significativa, já que em Alfenas os discentes terão acesso a uma maior gama de conteúdos relevantes para sua atuação na educação básica, podendo assim favorecer a construção de uma escola democrática.

Este dado é importante também para comprovar que no currículo básico dos cursos de licenciatura na UFSCar - Araras, por exemplo, a lacuna deixada por disciplinas que tratem da educação especial e inclusiva é grave. Ao pensarmos que o Pibid deve ser um campo privilegiado de relação entre a educação superior e a educação básica, a não apropriação de conhecimentos vinculados ao atendimento de alunos com NEE traz uma problemática que não pode ser ignorada: se nas políticas educacionais está declarada a busca pela construção de uma escola inclusiva, com vistas a atingir uma educação democratizada, como um programa que busca aprimorar a formação inicial e continuada de professores não trata de questões centrais para o processo inclusivo? Que 
tipo de ações o Pibid poderia proporcionar para a efetiva contribuição à formação de um professor preparado a atender as necessidades de alunos com NEE?

Concordamos com Nóvoa (1997), que na discussão da formação docente a ênfase deve ser atribuída à necessária diversificação dos modelos e práticas, que possibilitem relações diferenciadas entre o saber pedagógico e científico. Formação esta que necessariamente parte da experimentação, e de uma reflexão crítica sobre sua utilização, em um processo contínuo de investigação-ação.

Entretanto, quando analisamos os resultados apontados, não podemos desconsiderar que este cenário, nada animador ao se considerar a atuação dos licenciandos e a autoavaliação da falta de formação para esta prática, pode estar relacionado a pouca expressividade das experiências de apoio por profissionais da educação especial, levando em consideração que apenas $23,4 \%$ dos participantes do município de Araras e 4,3\% dos participantes do município de Alfenas, apontam terem vivenciado essas experiências de trabalho, nas quais estavam presentes profissionais de apoio.

Apesar desta constatação, em ambos os municípios ficou evidente que os pibidianos (92,3\% em Araras e 87,0\% em Alfenas) consideram que o auxílio de profissionais da educação especial para a elaboração de estratégias pedagógicas é importante para a efetivação da inclusão. Em Araras o teste Qui-Quadrado $\left(\chi^{2}=9,308\right.$; $\mathrm{ngl}=1 ; p=0,02)$ nos mostra que este resultado é significativo, entretanto, embora possamos aceitar o mesmo resultado para o município de Alfenas $\left(\chi^{2}=28,82 ; n g l=2\right.$; $p=0,00$ ), não podemos fazer tal afirmação já que o nível de significância foi igual a zero, apontando que a chance de ter ocorrido um erro é alta 5 .

Estes dados nos levam novamente a refletir sobre a importância da discussão acerca de como vem ocorrendo a formação inicial nos cursos de licenciatura, pois no que tange à educação especial e inclusiva ainda encontramos brechas e faltas grandes a serem sanadas, que precisam ser focadas de forma enfática, contando com o apoio de programas como o Pibid.

\footnotetext{
${ }^{5}$ Alguns autores vêm levantando discussões sobre a interpretação de quando temos $p=0,00$. No nosso caso, como a probabilidade associada ao valor de $\chi^{2}=28,82$, com 2 graus de liberdade é 0,00 , temos que se a hipótese nula for verdadeira, esse valor de $\chi^{2}$ dificilmente irá acontecer (que no nosso caso a chance de ocorrência é de uma em cem, pois adotamos o uso de duas casas decimais). Neste caso, podemos aceitar que existe uma diferença significativa entre os valores observados e os esperados, mas não fazer tal afirmação. Este fato está associado ao número de nossa amostra ser pequena, o que favorece a ocorrência de erros nos testes de hipóteses.
} 
Outra questão importante é a concepção de inclusão apresentada pelos pibidianos nos questionários. Notamos que de forma geral todos os bolsistas apontaram que a inclusão escolar volta-se para o atendimento de todos os alunos em escolas regulares, independente de suas características e particularidades.

Pela Política Nacional de Educação Especial na Perspectiva da Educação Inclusiva de 2008, o processo inclusivo é entendido como:

(...) paradigma educacional fundamentado na concepção de direitos humanos, que conjuga igualdade e diferença como valores indissociáveis, e que avança em relação à ideia de equidade formal ao contextualizar as circunstâncias históricas da produção da exclusão dentro e fora da escola (BRASIL, 2008, p.5).

Verificamos então que os pibidianos expressaram suas concepções de forma concernente ao entendimento legal. Entretanto, apesar deste eixo comum nas respostas, houve diferenças importantes entre as respostas de Araras e Alfenas. Enquanto em Araras os discentes voltaram-se à inclusão de alunos com NEE na escola regular, tendo garantido o processo de aprendizagem e socialização, alguns discentes de Alfenas destacaram o papel socializador da inclusão, voltando-se especialmente para alunos com deficiência. Em Alfenas também foi apontada a necessidade de preparação e capacitação de professores por dois bolsistas. A seguir estão destacadas algumas falas representativas das respostas dos pibidianos:

De um modo geral, a inclusão escolar seria a inserção dos alunos com Necessidades Educacionais Especiais nas escolas comuns, pois estes estavam e ainda estão condicionados ao ensino separado do ensino comum, ou seja, em escolas que continham apenas alunos com NEE (informante 4-Ar).

A inclusão escolar é para que os alunos com necessidades especiais possam estar cursando as disciplinas com alunos ditos normais, para que ele se socialize e possa conviver em sociedade (informante 16$\mathrm{Al})$.

Ao pensarmos na definição proposta pela política de educação especial de 2008, a educação inclusiva cumpre papel fundamental na busca por oportunidades educacionais e de socialização para todos os indivíduos, com ou sem NEE. Entretanto, assim como apontado anteriormente precisamos estar atentos ao fato de que a inserção do aluno em uma escola regular não garante sua participação no processo educacional, 
podendo gerar situações perversas de inclusão e o não cumprimento do papel fundamental da escola, tal como proposto por Saviani (2008) e discutido anteriormente.

Ainda no que se refere às concepções dos licenciandos em relação à inclusão de alunos com NEE, o questionário levantou os aspectos favoráveis e desfavoráveis deste processo, conforme disponibilizado no quatro 1:

Quadro 1: Aspectos favoráveis e desfavoráveis da inclusão escolar/educacional

\begin{tabular}{c|c}
\hline Aspectos favoráveis & Aspectos desfavoráveis \\
\hline Educação para todos & Inclusão marginal \\
\hline Socialização & Falta de infraestrutura \\
\hline Diminuição de preconceitos, estereótipos & Constrangimento inicial \\
\hline Investimento do estado & Déficit na formação de professores \\
\hline Desenvolvimento da sociedade & Pouco investimento \\
\hline Direito à educação & Dificuldades metodológicas \\
\hline Convivência com a diversidade & Falta de profissionais e recursos \\
\hline Estimulação do desenvolvimento & Problemas de infraestrutura \\
\hline Acessibilidade & Bullying \\
\hline & Discriminação em espaços escolares \\
\hline & Grande número de alunos em sala de aula \\
\hline
\end{tabular}

Fonte: autoras

Ao analisarmos os questionários notamos que os aspectos favoráveis apontados com maior frequência pelos pibidianos foram a educação para todos e a socialização, o que vai ao encontro do discurso veiculado pelo governo e pela mídia, já que estas instâncias pouco discutem os fatores perversos existentes no processo inclusivo. Quanto aos aspectos desfavoráveis, grande parte dos bolsistas indicou problemas na formação docente e na disponibilidade de recursos e infraestrutura adequada para atender os alunos com NEE. Muito já se discutiu acerca do déficit na formação docente, e apesar da Declaração de Salamanca, marco no processo de inclusão de alunos com NEE, ter sido elaborada em 1994 (aproximadamente há duas décadas) ainda encontramos nos discursos de gestores, professores e licenciandos o despreparo para atender este alunado, o que muitas vezes vem a deflagrar práticas de exclusão e inclusão marginal dos alunos com NEE, sendo desconsideradas suas potencialidades e progressos educacionais.

Prietro (2003) afirma que a formação inicial e continuada do professor é uma das tarefas mais importantes para que se alcance a qualidade de ensino, porém, além desta formação é preciso que a escola tenha acesso a novos conhecimentos derivados de pesquisas atuais que possam subsidiar o trabalho educacional. A formação de 
professores deve estar baseada na indissociação teórico-prática, contribuindo assim para o atendimento adequado das necessidades dos alunos, sendo esses com ou sem NEE.

Segundo os dados do Plano Nacional de Educação de 2001 (PNE/01), sugere-se que a situação referente à formação de professores para a educação especial é boa, considerando-se que aproximadamente $46 \%$ dos professores têm formação em ensino superior. Porém, esta situação pode ser analisada por outra perspectiva, já que mais da metade dos professores que trabalham com educação especial era formada em nível médio, de acordo com a afirmação que segue:

Se para todas as mazelas da educação comum a justificativa tem recaído sobre a má qualificação dos professores, por que, nesse caso, não é necessário que todos os professores atuantes no ensino especializado tenham formação específica em educação especial somada à formação em nível superior? (PRIETRO, 2003, p. 140).

No Plano Nacional de Educação de 2011 não se fala em porcentagem da formação docente para a educação especial, mas na meta quinze propõe-se a garantia "em regime de colaboração entre a União, os Estados, o Distrito Federal e os Municípios, que todos os professores da educação básica possuam formação específica de nível superior, obtida em curso de licenciatura na área de conhecimento em que atuam" (PNE 2011/2020). Esta meta e suas estratégias torna clara a existência de professores atuantes que ainda não possuem nível superior, ou que atuam em áreas distintas à sua formação inicial.

Prietro (2003) alerta que apesar da consideração da formação de professores em educação especial como boa no PNE/01, neste mesmo documento e também no PNE/11 está expressa a necessidade de formação dos professores das escolas regulares para atender aos alunos com NEE, uma vez que seu atendimento deve ser preferencialmente nas classes comuns destas escolas.

Por fim, cabe ressaltar que a partir da análise do corpus de dados desta pesquisa algumas ações foram estabelecidas na tentativa de aproximação entre a atuação dos pibidianos na escola e sua formação universitária, tais como: oferecimento de duas Atividades Curriculares Integradoras de Ensino, Pesquisa e Extensão ${ }^{6}$ com enfoque na

6 “As Atividades Curriculares de Integração Ensino, Pesquisa e Extensão (ACIEPEs) são uma experiência educativa, cultural e científica que, articulando o Ensino, a Pesquisa e a Extensão e envolvendo professores, técnicos e alunos da UFSCar, procura viabilizar e estimular o seu relacionamento com diferentes segmentos da sociedade" (UFSCar, http://www.proex.ufscar.br/site/menu-1/aciepes). Na experiência específica destas ACIEPEs foi possível favorecer a discussão entre os licenciandos e professores e diretores do ensino regular e especial, levando em consideração as experiências desenvolvidas no Pibid e tendo em vista este programa como "parceiro" e co-responsável na formação inicial e continuada. 
educação especial/inclusiva e no processo de desenvolvimento e aprendizagem a partir dos pressupostos da Teoria Histórico-Cultural; disciplina optativa com caráter teóricoprático acerca dos Fundamentos da Educação Inclusiva; grupo de estudos com os pibidianos com o objetivo de analisar as práticas desenvolvidas e suas vinculações com a formação universitária.

\section{Considerações, que não finalizam...}

Este estudo buscou analisar as concepções e entendimento de discentes bolsistas do Pibid acerca do processo inclusivo, a partir de sua interface com a formação docente e a inclusão de alunos com NEE no ensino regular. Não nos propomos a quaisquer generalizações, apenas buscamos entender as concepções dos informantes da pesquisa, bem como suas experiências em prol da análise de como espaços de formação inicial e continuada, como o Pibid, estão oportunizando ou não discussões que favoreçam a busca pela efetivação do processo inclusivo e da construção de uma educação democrática em nosso país.

Notamos que os participantes deste trabalho apontam para a importância da preparação para a atuação com alunos com NEE, bem como do auxílio de professores especializados para a concretização do processo inclusivo. É com preocupação que verificamos que parte significativa destes discentes não se consideram responsáveis pela execução de práticas pedagógicas inclusivas, o que pode ser considerado como fato grave ao levarmos em consideração que se tratam de alunos de cursos de licenciatura que em um futuro próximo atuarão no ensino regular, no entanto, não podemos desconsiderar que o fato de não terem até então vivenciado experiências inclusivas, com o apoio e respaldo necessário, pode favorecer posicionamentos como este.

Ao considerarmos os pressupostos da teoria histórico-cultural, no que se refere aos alunos com NEE, em especial aqueles com uma deficiência, é essencial pensarmos em como os professores podem favorecer mecanismos de compensação social, que busquem a superação de limites e dificuldades impostos por condições estruturais. Pensando que a deficiência impõe uma consequência social que pode ser minimizada pela estruturação de vias alternativas de desenvolvimento e aprendizagem, torna-se que a formação profissional de professores esteja atenta às necessidades da diversidade do 
alunado, sendo o espaço formativo do Pibid um campo importante e privilegiado para favorecer esta estruturação.

Com base nas análises, considerações e questões levantadas, ressaltamos a importância da discussão acerca da formação inicial e continuada de professores para o atendimento das necessidades específicas de alunos com NEE na busca por uma educação democrática e de qualidade. Enfatizamos também que, neste momento histórico em que o governo favoreceu a expansão dos cursos de licenciatura e tem apoiado programas de formação inicial e continuada, tal como o Pibid, precisamos avaliar como estes incentivos vêm contribuindo para o efetivo aprimoramento na formação teórico-prática dos licenciandos. Esta avaliação se torna essencial ao buscarmos uma educação voltada para a formação de cidadãos críticos, reflexivos e atuantes em nossa sociedade.

AGRADECIMENTOS: FAPESP; FAPEMIG.

\section{REFERÊNCIAS}

AMARAL, L.A. Diferenças, estigma e preconceito: O desafio da inclusão. In: OLIVEIRA, M.K.; SOUZA, D.T.R.; REGO, T.C. (orgs). Psicologia, educação e as temáticas da vida contemporânea. São Paulo: Moderna, 2002.

ANDRE, Marli. Políticas e programas de apoio aos professores iniciantes no Brasil. Cadernos de Pesquisa, São Paulo, v. 42, n. 145, p. 112-129, abr. 2012.

BASTOS, M. B. Inclusão Escolar: um trabalho com professores a partir de operadores da psicanálise. Dissertação de Mestrado - não publicada. Universidade de São Paulo Instituto de Psicologia. São Paulo, 2003. 133p.

BRASIL. Política Nacional de Educação Especial na perspectiva da Inclusão. 2008. Ministério da Educação. Disponível em: <www.portal.mec.gov.br.>. Acesso em: 20 fev. 2009.

BRASIL. Congresso Nacional. Decreto n.7.611, de 17 de novembro de 2011.

Disponível em: <http://www.planalto.gov.br/ccivil_03/_Ato2011-

2014/2011/Decreto/D7611.htm>. Acesso em: 05 de nov. de 2012.

BRASIL. Plano Nacional de Educação 2011/2020. Disponível em:

$<$ http://portal.mec.gov.br/index.php?option=com_content $\&$ view=article\&id=16478\&Ite mid=1107>. Acesso em: 05 de nov. de 2012. 
BRASIL. Plano Nacional de Educação 2001/2010. Disponível em:

<http://portal.mec.gov.br/arquivos/pdf/pne.pdf>. Acesso em: 05 de nov. de 2012.

EMILIO, S. A. O cotidiano escolar pelo avesso: sobre laços, amarras e nós no processo de inclusão. Tese de Doutorado - não publicada. Universidade de São Paulo. Instituto de Psicologia, 2004.

DARROZ, Luiz Marcelo; WANNMACHER, Clóvis Milton Duval. Aprendizagem docente no âmbito do PIBID/Física: A visão dos bolsistas de iniciação à docência. Ensino e Pesquisa em Educação em Ciências, Belo Horizonte, v. 17, n. 3, p. 727 748, dez. 2015.

FRANCA, C. C. Políticas de identidade e estratégias identitárias: relflexões sobre a dinâmica de relações exclusão/inclusão no contexto escolar. Tese de doutorado - não publicada. Pontifícia Universidade Católica de São Paulo. Psicologia da Educação, 2005.

GATTI, B. Formação de professores: condições e problemas atuais. Revista Brasileira de Formação de Professores.- Revista Brasileira de Formação de Professores, Vol. 1, n. 1, p.90-102, Maio/2009.

LEVIN, J. Estatística para as ciências humanas. São Paulo: Pearson Education do Brasil, 2012. 458 p.

LIBANEO, J. C.; OLIVEIRA, J. F. e TOSCHI, M. S. Educação Escolar: políticas, estrutura e organização. São Paulo: Cortez, 2012. 543p.

MARTINS, J.S. A sociedade vista do abismo: novos estudos sobre exclusão, pobreza e classes sociais. 2 ed. Petrópolis: Vozes, 2002. 228 p.

MICHELS, M. H. Gestão, Formação Docente e Inclusão: eixos da reforma curricular educacional brasileira que atribuem contornos a organização escolar. Revista Brasileira de Educação. v. 11, n. 33, set/dez, p. 406 - 423, 2006.

NÓVOA, A. (org.). Os professores e a sua formação. 3 ed. Lisboa: Publicações Dom Quixote, 1997.

PATTO, M.H.S. Políticas atuais de inclusão escolar: Reflexão a partir de um recorte conceitual. In: BUENO, J.G.S.; MENDES,G.M.L.; SANTOS, R.A. Deficiência e escolarização: novas perspectivas de análise. Araraquara: Junqueira e Marin; Brasilia: CAPES, 2008.

PESSINI, M. A. Um estudo qualitativo: alunos portadores de deficiência no ensino superior. Dissertação de mestrado - não publicada. Pontifícia Católica do Rio Grande do Sul. Faculdade de Psicologia, 2002.

PRIETRO, R.G. Formação de professores para o atendimento de alunos com necessidades educacionais especiais: diretrizes nacionais para a educação básica e a educação especial. In: SILVA, S.; VIZIM, M. (orgs). Políticas públicas: educação, 
tecnologias e pessoas com deficiência. Campinas: Mercado de Letras: Associação de Leitura do Brasil, 2003.

SANTOS, Valéria C.; ARROIO, Agnaldo. A formação de professores em comunidades de prática: o caso de um grupo de professores de Química em formação inicial.

Química Nova, São Paulo, v. 38, n. 1, p. 144-150, jan. 2015.

SAVIANI, D. Pedagogia Histórico-Crítica. 10 ed. Campinas, SP: Autores Associados, 2008.

VIANA, F. M. G. Política de Inclusão e a formação de professores. Dissertação de mestrado - não publicada. Universidade de São Paulo. Faculdade de Filosofia, Ciências e Letras de Ribeirão Preto, 2005.

\section{Como referenciar este artigo}

BAZON, Fernanda Vilhena Mafra.; LOZANO, Daniele.; GOMES, Claudia. O processo inclusivo nos municípios de Araras e Alfenas no entendimento de licenciandos bolsistas do PIBID. Revista Ibero-Americana de Estudos em Educação, Araraquara/SP, v. 11, n. $3, \quad$ p.1496-1518, 2016. Disponível em: <https://dx.doi.org/10.21723/riaee.v11.n3.6017>. E-ISSN: 1982-5587.

Submetido em: 25/06/2013

Aprovação final em: 01/08/2016 
RIAEE - Revista Ibero-Americana de Estudos em Educação, v. 11, n. 3, p.1496-1518, 2016 DOI: https://dx.doi.org/10.21723/riaee.v11.n3.6017 